\title{
Energy Efficiency in Industrial Areas: Application of Best Practices for Energy Efficiency In Mediterranean Industrial Areas
}

By

\author{
Maria-Anna Segreto* ${ }^{1}$, Marcello Artioli ${ }^{1}$, Rovena Preka ${ }^{2}$ and \\ Mario Tarantini ${ }^{3}$
}

\begin{abstract}
:
The results presented in this paper originate from an EU research project that is near to its completion. The goal was to build a model that can be applied to all industrial sites in the Mediterranean area. The approach followed to achieve the objectives was to study all the new technologies and systems that, if applied globally, can make the whole area sustainable both energetically and environmentally. The application of the model allows the design and implementation of self-sufficient green areas in terms of energy which also brings to the reduction of the emissions into the atmosphere. An aim of the project was also to identify possible sources of funding or incentives. The main beneficiaries of the results are SMEs that through a more responsible approach to the environment could get greater market competitiveness and reduce energy costs of their enterprises. Other beneficiaries are the people who obtain advantages from a clearer and less polluted surrounding environment.

The paper presents the results obtained from the application of the model in some pilot cases.
\end{abstract}

Key words: industrial areas, industrial Buildings, energy efficiency, energy audit, Mediterranean areas.

\section{Introduction}

According to "World Energy Outlook 2012" (WEO), global energy demand grows by more than one-third over the period to 2035 in the New Policies Scenario. It was recognized that energy efficiency is the key that

1 Researcher, Energy Efficiency Technical Unit, ENEA - Italian National Agency for New Technologies, Energy and Sustainable Economic Development, Bologna, IT

2 Researcher, Technical Unit for Environmental Assessments, ENEA - Italian National Agency for New Technologies, Energy and Sustainable Economic Development, Bologna, IT

${ }^{3}$ Senior Researcher, Technical Unit for Environmental Assessments, ENEA - Italian National Agency for New Technologies, Energy and Sustainable Economic Development, Bologna, IT

*Corresponding Author 
decision-makers have in their hands for a more sustainable development and a more rational use of the resources now available.

The proposed scenario in WEO-2012 shows that the culling of barriers to investment in energy efficiency gives the opportunity to achieve enormous gains for energy security, economic growth and the environment. This confirms that the application of policies that implement economically feasible energy efficiency measures would have important implications on global climate and energy trends. Therefore it becomes essential that policy makers improve the accessibility to energy efficiency, creating and supporting business models, financing instruments and incentives, in order to provide investors with an adequate financial return.

Based on the experiences and developments of energy policies that have seen an increasing integration of environmental decisions with the energy one (Greening and Bernow, 2004), the EU has defined a strategy to reduce greenhouse gas emissions.

The EU strategy has three different main objectives: the 20\% reduction of primary sources consumption, the $20 \%$ reduction of greenhouse gas emissions, the $20 \%$ increase of the share of renewable sources in the final consumption (electrical, heating and transport use).

As regards to these objectives it is useful to remember the huge contribution made by the wide community programming, which has offered a new life to the project initiatives presented by the Member States through a series of financed programs that help to improve energy efficiency, cutting of $\mathrm{CO}_{2}$ emissions and the increase of renewable sources use.

In this scenario it has a great importance also the 2010/31/UE Directive, by proposing guiding principles for Member States about energy performance of buildings.

It is well known that the highest energy consumption in industrialized countries affects the industrial and the residential sectors (buildings sector represents $40 \%$ of the European Union's total energy consumption). The introduction of the Directive points out that: "Member States should authorize and encourage designers and planners to appropriately value the optimal combination of improvements in energy efficiency, the use of renewable sources and the use of heating/cooling district during the planning, design, construction and renovation of industrial or residential areas", confirming that reducing energy consumption in this sectors is therefore a priority under the “20-20-20" objectives on energy efficiency.

It is a common perception that energy efficiency in industry is too complex to be tackled: this paper aims to demonstrate that it is possible to achieve excellent results of efficiency even in industry through the application of an appropriate design methodology. 


\section{MEID Project}

The Mediterranean Eco-Industrial Development (MEID) project is an initiative co-financed by the Med Program and the European Regional Development Fund.

MEID aims at realizing the Mediterranean Eco Industrial Development model by facilitating and enabling planning, building and governing sustainable Industrial Areas (IAs).

It is based on a new concept of industrial areas management: a Sustainable Industrial Area (SIA) equipped and settled with technical and organizational requirements in order to decrease the pollution, its pressure on environment and improve its energy efficiency. This new concept can increase the potential economic value and foster the local community acceptance.

Output of the project is a methodological model to plan, build and manage the industrial areas in Mediterranean Regions in a competitive way, improving sustainable development and SMEs competitiveness. The project associates ten partners of five Mediterranean countries (Italy, France, Spain, Greece, Malta) and Bosnia-Herzegovina under the leadership of ENEA, the Italian National Agency for New Technologies, Energy and Sustainable Economic Development. The model intends to enhance capacities and to develop decision tools for competent authorities and industrial area managers to integrate environmental friendly solutions into the regional and interregional industrial development strategies, defining a correct equilibrium among public and private interests.

The key elements of the MEID management model are shown in the picture of Fig.1:

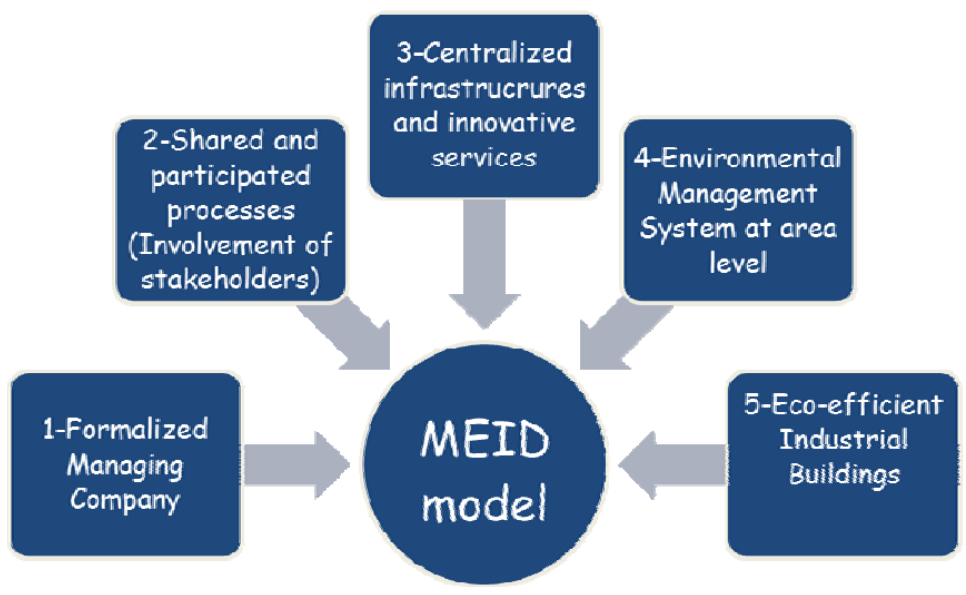

Fig. 1: MEID management model 
An incremental approach has been adopted to ensure the model applicability to new industrial areas, as well as to already operating structured and non structured areas.

An essential element of the MEID model is the presence of a Managing Company (MC), whose functions are decisive for the area development. The process of conversion to SIAs can be started, in fact, by adopting a common area management system leaded by the MC, which can support the settled companies to act as a single entity. They could profitably use the opportunities offered by shared services and infrastructures in the area and collaborate with Local Authorities to define voluntary agreements and action plans aiming at the improvement of the economic, environmental and social performances of the area. Besides, the involvement of stakeholders in the management decisions of the IA is a fundamental step of the model.

The common infrastructures and innovative centralized services could be managed directly, or through third parts, by the MC which, in any case, will have to guarantee the quality of the delivered services. Among the infrastructures, a specific attention should be given to industrial buildings, which can be a source of energy saving and innovation.

For this goal the project MEID has focused large part of its activity on the actions to be taken to make industrial buildings more efficient or nearly selfsufficient.

Finally, an Environmental Management System of the area should be implemented through the following steps:

- definition of the area policy and the macro objectives of sustainability;

- analysis of the environmental and energetic aspects and detect the significant ones;

- definition of a shared improvement plan;

- implementation of a monitoring system of the area's performance;

- definition of the procedures for the internal/external communication.

A detailed database on Best Available Practices has been developed in the MEID project as supporting tool for industrial area managers. The database refers to industrial areas of the Mediterranean region, in particular in the MEID partner's countries. The selected good practices include both infrastructures and innovative services of the industrial area (http://www.medmeid.eu/theproject/results-and-deliverables/bat-database/).

The management model has already been partially implemented and will be implemented during this year in three selected pilot areas located in the Mediterranean regions, partners of the project: Ragusa (Italy), Padova (Italy) and Valencia (Spain). According to their stages of development and depending on 
whether they are new or already existing ones, the MEID model will be applied differently.

\section{Energy efficiency actions}

The goal of this paper is to illustrate the undertaken actions in MEID to make the industrial areas (and especially industrial buildings) more efficient and less energy consuming.

The decision-makers within the companies have often an one-dimensional concept of industrial energy consumption, considering it only an unavoidable cost that can be managed just through a lower utilization. The well-advanced producers are, however, looking for an answer to the problem of energy management by facing it as a three-dimensional challenge: reduce, spending less and optimize.

In many cases, energy is inefficiently used and it would be enough to make simple changes in behavior and programming, to reach a more productive use of energy: using less energy, for example, through an intelligent scheduling of the production, using more efficient equipment or improving the design by re-using the processes residual heat. Less expensive energy may also be used by managing delivery points and timing, scheduling high power activities during time slots of lower demand.

In order to correct energy managing in industry, the building envelope has an important role: each envelope is permeable, to a greater or lesser extent, towards the external environment and this permeability, if properly managed, can allow obtaining relevant savings.

The application of the MEID methodology requires that the issues related to consumption and sustainability must be addressed on two levels: a micro-level, which covers the single production unit, and a macro-level which covers the whole area and refers to all the elements that surround the individual company (internal transport systems, services, green areas...) and connect each building to the others, creating a single entity that has been called SIA.

With regard to the micro-level the main element is, of course, the industrial building, used for the production of goods and services, whose design must also include production systems. Therefore it must be taken into account the relationship between the building and the productive process because it plays a decisive role in the project choices in order to determine its energy performance. The methodology used for assessing the energy efficiency of industrial buildings is founded on some basic considerations: an industrial area can be split into multiple components, closely related. To get the best analysis it is very important that in the evaluation phase each component is never disconnected from others. The main components that must be considered are: the envelope and the plant. 
The envelope is a filter between internal and external environment, therefore, its function can be compared to human skin which regulates the internal temperatures dynamically as a function of the external climatic conditions. It will be evaluated, analyzed and studied according to two important components: insulation and envelope dynamicity

In case of self-sustaining and high efficiency industrial areas, the plant should be considered as a macro component of the area, not as an individual one and it is split into several complex components: the plant systems, the distributed generation and renewable energy use.

The two components (envelope and plant) are jointed and integrated by a condition that amplifies the efficacy of the identified efficient solutions: the automation (Fig. 2).

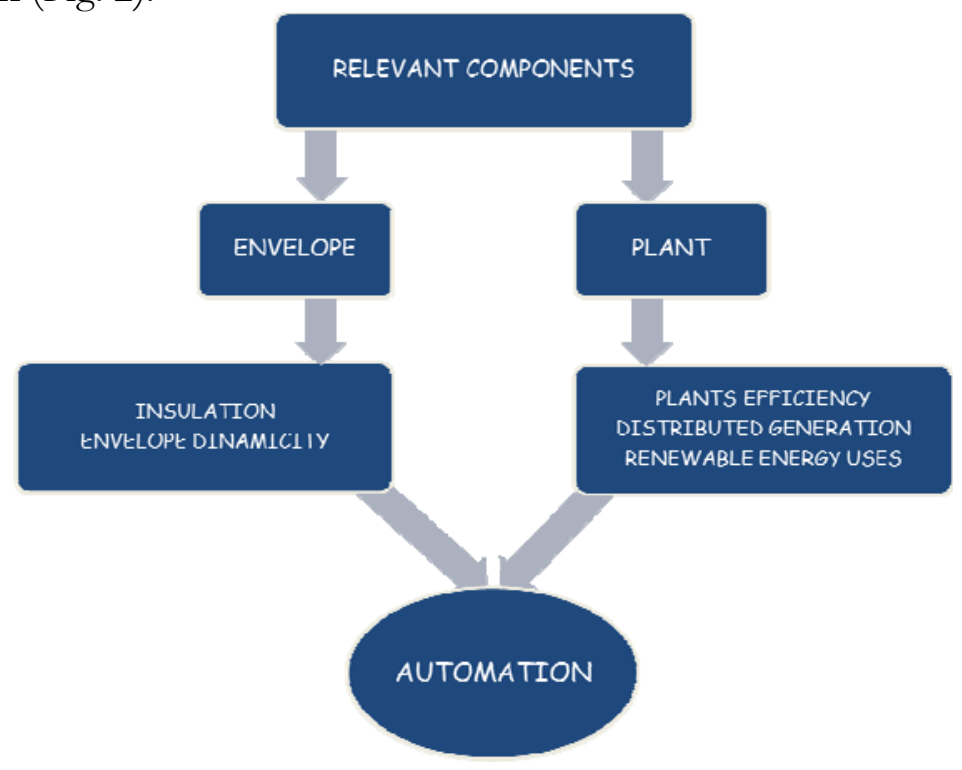

Fig.2: Analisys scheme to apply MEID methodology

The insulation is the first important element that is evaluated. The analysis can be applied to both existing and new buildings. For existing buildings it starts with a thermographic measurements through a thermocamera that can sense the temperatures of architectural elements (walls, floors, roofs...) by measuring the intensity of infrared radiation emitted by the element. It allows evaluating how much heat is dissipated to the outside and detecting the most dispersive building elements. Next step is the evaluation of the most appropriate solution.

If the building is a new construction, the elements are freely modeled with software tools with the only constraint on the due values of transmittance. The modeling should verify the correct positioning of materials, the insulation 
performance in winter, and attenuation and phase shift of the thermal wave (required analysis in the Mediterranean areas) in summer. In this case, the design takes into account energy-saving techniques and materials from the beginning.

An important feature to be related to the insulation is also a careful thermohygrometric check. If it is not satisfied, in fact, there is a high risk of creating molds and wetlands with consequent deterioration of both healthiness and energy efficiency. The designers often do not consider that the condensation phenomenon may also occur due to a bad combination of materials in the walls or floor stratigraphy. In the MEID project many simulations were carried out and the results have shown that the position of a material and its compatibility with another one can give good results in terms of insulation, while they can give poor ones in hygrothermal terms.

Today there are many conventional high performance technical solutions for new industrial or existing buildings. In the case of MEID project, it has been chosen the use of innovative materials: envelope with different types of phase change materials (PCM) (powders, packeted, microcapsules...). These solutions allow an annual saving of approximately $40 \%$ compared to a conventional solution. Further modeling were made by applying active wall systems (ventilated facades or glass double skin facades) that create a dynamic envelope where walls modify their performance according to the outside weather conditions. These solutions, applied in Mediterranean areas, provide extremely high savings (50$60 \%$ ), especially when joined with green roofs. In the pilot case of the Eco Industrial Area of Ragusa (Italy) such solutions have been provided, demonstrating that the building can be considered a nearly zero energy building.

Also with regard to the plant, especially in existing ones, we can find severe conditions of inefficiencies due to mainly bad maintenance and management of the equipment. Even in this case more efficient techniques and materials are available to improve energy performance.

An innovative application that has been studied in the project is the cogeneration. A cogeneration plant supplies electricity and thermal energy obtained from a single source (primary energy) in a single integrated system. If this system is also implemented to produce cooling energy we obtain a trigeneration plant.

These systems have very high efficiency and they have found numerous applications in the industry sector. In recent years they are also used in residential buildings to replace conventional boilers.

The performed simulations in pilot buildings have shown several advantages both economic (25-40\% with a pay-back period of the investment of around 3650 months) and in performance (70-85\%).

In respect to the plants, in order to give a renewed impulse on energy efficiency, the European Commission presented a new energy efficiency plan 
containing measures to achieve additional savings in the supply and use of energy. The 2012/27/EU Directive includes, among other points, also distributed generation, renewable sources use and high efficiency cogeneration: three priorities of political and economic strategy for the coming years.

The relocation of production facilities on the territory can be indicated as distributed generation. It usually occurs in the presence of free private enterprise development in the field of renewable energy. It represents a different way of thinking and managing the power grid, not based on large power plants connected to extensive networks, but on production units of small-medium size, evenly distributed on the territory and connected directly to utilities or other low voltage networks.

The distributed generation is the only form of generation that allows the diversification of energy carriers and the exploitation of renewable energy resources. In this case, in fact, it can use different energy production systems which compensate each other using the network as a storage and distribution system.

One of the most important benefits of distributed generation is the shorter transmission line and more simple distribution networks and thus lower costs. The proximity of the energy plant to final points of consumption reduces dispersions as well: this is a big advantage because even today a high percentage of electricity produced is dispersed during transport. Distributed generation, moreover, increases network reliability, because a break down of a plant does not imply the interruption of power supply, because it is offset by the presence of other plants.

The design of an energy district with distributed generation has generally many issues. The fundamental problems are mainly related to difficulties in the simultaneous analysis of the interactions between building systems, power generation, variable thermoelectric utilities, variable climatic conditions, presence of renewable energy sources, performance restriction issues, economic and financial problems.

Trying to solve some of these analysis problems, we used ODESSE (Optimal DESign for Smart Energy), a software tool developed by ENEA (Bertini et al., 2009). It is able to simulate, in dynamic conditions, renewable energy sources integrated to distributed generation, working in real conditions. It offers a determinant support in evaluating the integration of more energy efficient technologies (renewable energy sources, cogeneration, solar cooling, etc...) according to specific characteristics (site, local context demands, energy rates...) in order to increase the energy efficiency and competitiveness (Ceravolo et al., 2010).

The simulations allowed assessing that a midsize power plant reaches $80 \%$ of the overall performance compared to $35 \%$ of the best large power plants. 
All the best solutions identified by the analysis of MEID pilot cases may be further improved in performance if managed with a smart automation system.

Improved energy efficiency in buildings is a high priority among European decision makers. Quoting Brissman and Ullmann (2011), "...presently there is one European standard that assists building owners to ensure that a new building being built, or an existing building being refurbished, will have the best available Building Automation and Control Sytem (BACS) technology to save energy - i.e. the EN 15232 - Energy performance of buildings - Impact of Building Automation, Controls and Building Management standard.

However, there are no standards available that address the difficult challenge of building owners to ensure that their buildings keep performing as well over time, or better, than when they were first commissioned."

Even if no standards are published, a sound state of the art can be found in literature (Dounis \& Caraiscos, 2009) and on the market as well.

The different approaches to control systems for indoor building environments can be summarized into the following categories:

- conventional methods;

- computational intelligence techniques;

- agent-based intelligent systems.

Even since the beginning, the minimization of energy consumption has been the main goal of the development of control systems for buildings: thermostats were used for the feedback control of the temperature. Due to the lack of flexibility (i.e. in controlling dead zones or overshooting), these conventional control systems evolved towards adaptive or predictive systems, for which a model of the building or of the usage scenario is needed.

They did not reach the market because of complex mathematical nonlinearity given by the models.

Next step (Singh et al., 2006) was to introduce approximations through fuzzy logic and neural networks to overcome such non-linear calculations, giving birth to the computational intelligence techniques onboard of the controller.

A further improvement has been the adoption of a network outside the single controller.

Agent-based intelligent systems are, in fact, a connection of distributed subsystems (Coen, 1997), each able to solve individual sub-problems (regulate temperature, control lightning, ecc) but also to interact with other sub-systems (human user comprised) and react accordingly.

Most building automation networks consist of a primary and secondary bus which connect high-level controllers (generally specialized for building automation, but may be generic programmable logic controllers) with lower-level controllers, input/output devices and an user interface (Fig. 3). 
Modularity and hierarchical structure allows taking into account tasks other than saving energy, like comfort (air quality, climatization, etc.) and security (access control, surveillance, etc.).

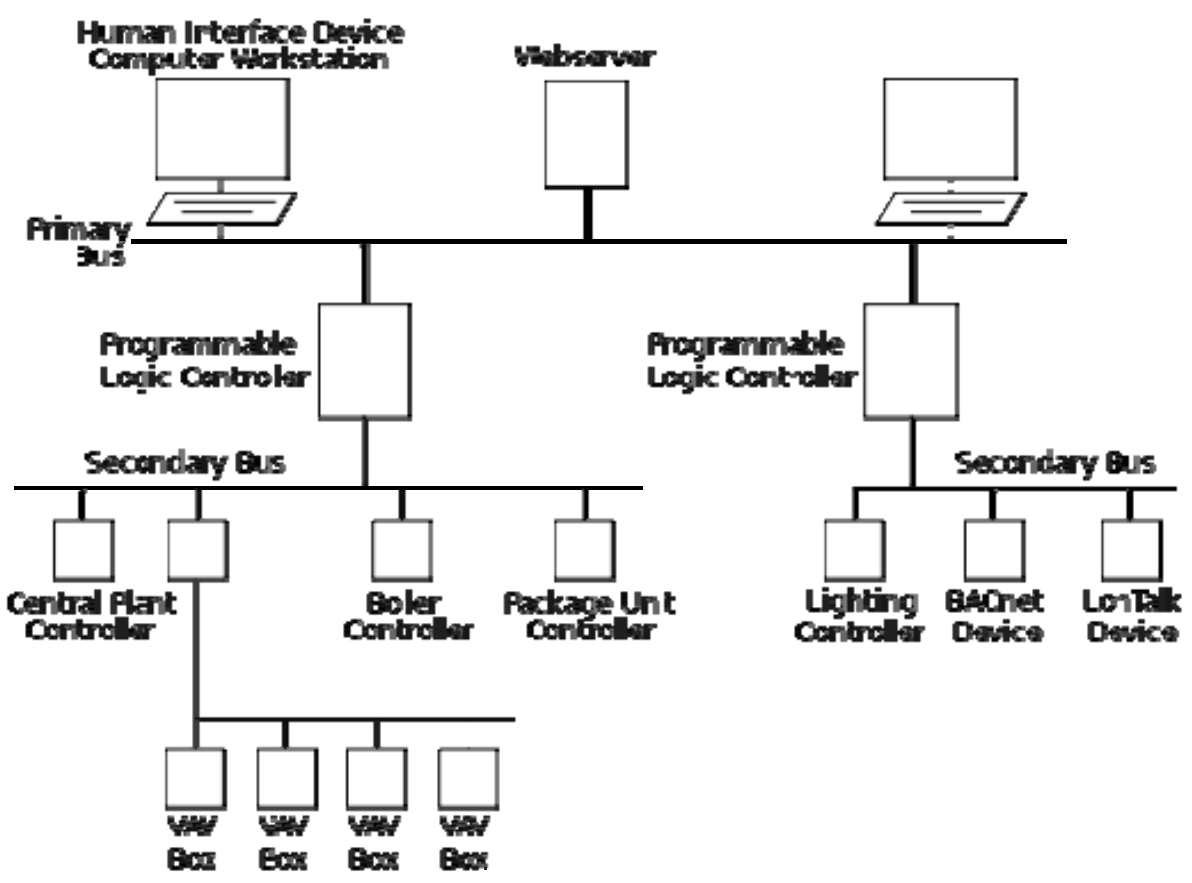

Fig. 3: Building automation network (from Wikipedia)

Automation systems can also be applied to implement energy efficiency in industrial processes.

Peak load and high energy consumption, for example, are issues that affect business decision makers. The solution of these problems can be reached using highly sophisticated computational intelligent algorithms that will be able to provide high quality production scheduling solutions (Marinakis and Panagiotis, 2012).

Automation technologies and industrial control used for optimal management of production facilities (manufacturing and processing) provide numerous opportunities for energy savings. In recent years, useful tools have been developed to help companies to improve their performances and to reduce energy costs.

The available tools are mainly based on three important steps:

- Energy monitoring and reporting

- Energy load planning 
- Energy optimization

These tools, matched to BACS for buildings management, complement the energy efficiency system allowing an increase in performance (compared to the situation without automation systems and control) from 5 to $15 \%$ in the design of a SIA.

\section{Conclusions}

All the experience and the analyses carried out in the MEID project have been collected in a guide that contains all the possible measures to be taken to make an existing or a new industrial building sustainable and energy efficient.

Through the use of software tools, the application of the measures (Ecologically Sustainable Construction for Industrial Buildings) allows obtaining, a numerical value for each area of intervention (energy, materials, drinking water, transport...) with a scoring system.

The same tools allow the evaluation of different alternatives, the analysis of intervention areas and the measure of their impact. In the final step of the analysis process, a "scorecard" is generated to show the results in different graphs for an easy interpretation (Fig. 4).

The pilot cases have been subjected to this analysis process.

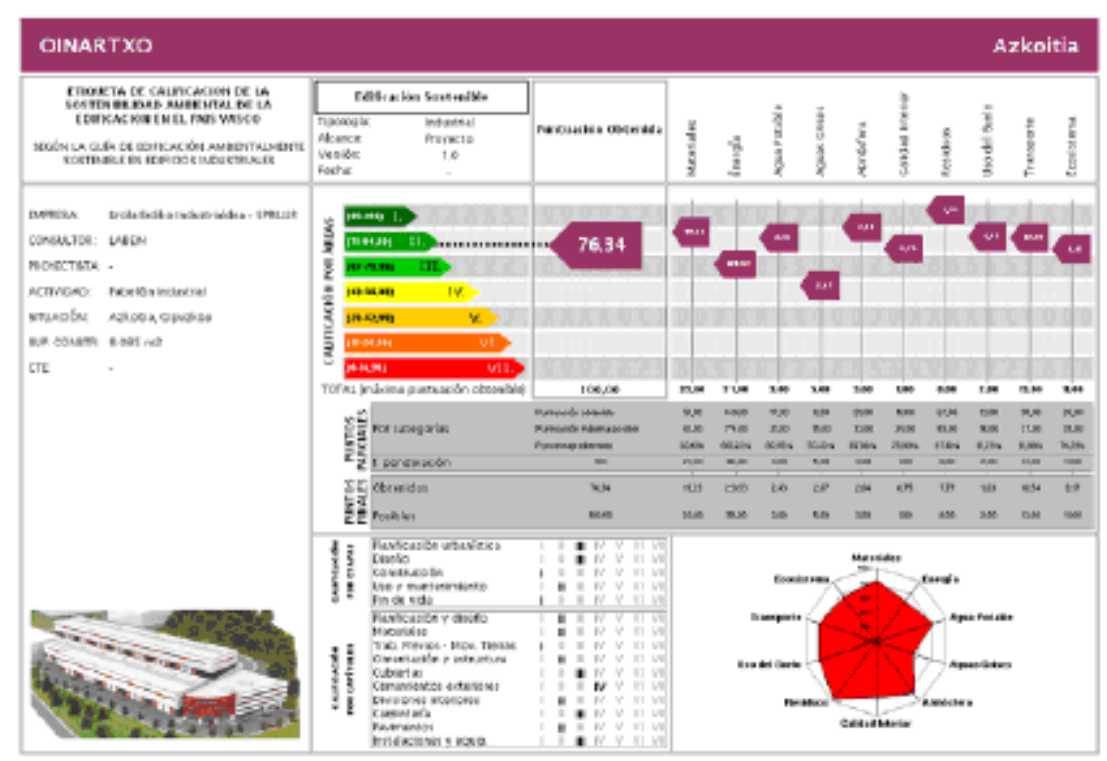

Fig. 4: Evaluation results

The key objective of the project is to disseminate this information among the largest number of stakeholders, although a great work has still to be done to complete the information transfer to the designers so that they can apply it into 
their daily planning. Another effort has been made (and will still be done) to propose and offer such instrument to policy makers so that it could be used as an important tool for energy efficiency and savings in industrial areas.

\section{References}

Greening L.A., Bernow S., (2004). Design of coordinated energy and environmental policies: use of multi-criteria decision-making. Energy Policy, 32 (2004) 721-735

Bertini I., Ceravolo F., De Felice M., Di Pietra B., Margiotta F., Pizzuti S., Puglisi G. (2009) Sviluppo dell'ambiente di progettazione Optimal DESign for Smart Energy - ODESSE. RSE/2009/188 Report

Ceravolo F., Di Pietra B., Margiotta F., Puglisi G. (September 2010). ODESSE: simulazione dinamica del sistema edificio-impianti per la climatizzazione estiva. RdS/2010/251 Report

Brissman, J., Ullmann, R. (2011, January). Improving Energy Efficiency with Building Automation and Control Systems (BACS). REHVA European HV AC Journal, 1, 28-30.

Dounis, A.I., Caraiscos, C., (2009, August-September). Advanced control systems engineering for energy and comfort management in a building environment- $\mathrm{A}$ review. Renewable and Sustainable Energy Reviews, 13(6-7), 1246-1261.

Singh, J., Singh, N., \& Sharma, J. K. (2006). Fuzzy modeling and control of HVAC systems - A review. Journal of Scientific and Industrial Research, 65(6), 470-476.

Coen, M. H. (1997). Building brains for rooms: Designing distributed software agents. Paper presented at the Innovative Applications of Artificial Intelligence - Conference Proceedings, 971-977.

Building automation network. In Wikipedia retrieved in March, 2013, from, http://en.wikipedia.org/wiki/Building automation

Marinakis Y., Panagiotis C. (July, 2012). Energy-aware enterprise systems for low-carbon intelligent operations. Artisan project deliverable D3.1 